\title{
Pseudomembranous supraglottitis with airway compromise in a patient with recurrent tonsillar carcinoma
}

\author{
[Supraglottite pseudomembraneuse avec séquelles sur les voies aériennes chez un \\ patient souffrant d'un carcinome amygdalien récidivant]
}

Thomas G. Klein DO, David G. Parkins MD, Sweeta D. Gandhi MD, Zafar Iqbal MD, William T. Schmeling MD PhD, Paul S. Pagel MD PhD

\begin{abstract}
Purpose: In this report, we discuss a patient with acute pseudomembranous supraglottitis complicating recurrent tonsillar carcinoma and describe the ramifications of these disorders on perioperative management.
\end{abstract}

Clinical features: The patient was an acutely ill man with a history of right tonsillar carcinoma originally treated with chemoradiation therapy and a radical neck dissection who presented with a brief history of fever, dyspnea, and stridor. The soft tissue of his neck was very stiff, his neck mobility was limited, and his mouth opening was restricted by pain and radiation-induced fibrosis. A nasal flexible fibreoptic laryngoscopy revealed a very large, indurated epiglottis almost completely obstructing the glottis. The aryepiglottic folds and false cords were edematous, and a gray pseudomembranous exudate was observed on the glottic surface, epiglottis, and true vocal cords. An elective tracheostomy was performed in the operating room using local anesthesia, and conscious sedation was avoided because of the potential for complete airway obstruction. General anesthesia was induced after the airway was secured, but trismus and tissue edema resulting from the acute infection made the glottis and surrounding structures nearly impossible to visualize during direct laryngoscopy. The patient was treated with intravenous antibiotics, and a subsequent direct laryngoscopy demonstrated tumour recurrence.

Conclusions: The case emphasizes that the perioperative management of imminent airway obstruction by acute supraglottitis complicating recurrent oropharyngeal cancer may optimally be approached by establishing a surgical airway under controlled operating conditions.

CAN J ANESTH 2008 / 55: 1 / pp 42-46
Objectif: Dans ce compte-rendu, nous rapportons le cas d'un patient souffrant d'une supraglottite pseudomembraneuse aiguë compliquant un carcinome amygdalien récidivant et décrivons les répercussions de ces troubles sur la prise en charge périopératoire.

Eléments cliniques : Le patient était un homme en phase aiguë de maladie et présentant des antécédents de carcinome amygdalien traité par chimiothérapie et dissection radicale du cou. II s'est présenté avec une histoire de fièvre, de dyspnée et de stridor. Les tissus mous de son cou étaient très rigides, la mobilité du cou très réduite, et l'ouverture de la bouche restreinte à cause de la douleur et d'une fibrose provoquée par la radiothérapie. Une laryngoscopie nasale par fibre optique flexible a montré une épiglotte énorme et indurée obstruant presque totalement la glotte. Les replis ary-épiglottiques et les fausses cordes vocales étaient oedémateux, et un exsudat gris pseudomembraneux a été observé sur la surface glottique, l'épiglotte, et les vraies cordes vocales. Une trachéostomie élective a été réalisée en salle d'opération sous anesthésie locale, et une sédation consciente a été évitée à cause du risque potentiel d'obstruction totale des voies respiratoires. Une fois les voies aériennes contrôlées, l'anesthésie générale a été réalisée, mais un trismus et un œdème tissulaire provoqués par l'infection aiguë ont rendu une visualisation de la glotte et des structures alentour quasi-impossible pendant la laryngoscopie directe. Le patient a été traité par des antibiotiques intraveineux, après quoi une laryngoscopie directe a montré une récidive de la tumeur.

Conclusions : Ce cas souligne le fait que la prise en charge périopératoire d'une obstruction imminente des voies respiratoires par supraglottite aiguë compliquant un cancer oropharyngien récidivant puisse être idéalement menée en établissant un accès aux voies aériennes par la chirurgie dans des conditions d'opération contrôlées.

From the Anesthesia Service, the Clement J. Zablocki Veterans Affairs Medical Center, Milwaukee, Wisconsin, USA.

Address correspondence to: Dr. Paul S. Pagel, Clement J. Zablocki Veterans Affairs Medical Center, Anesthesia Service, 5000 W. National

Avenue, Milwaukee, Wisconsin 53295, USA. Phone: 414-384-2000, ext. 42417; Fax: 414-384-2939; E-mail: pspagel@mcw.edu

This work was supported entirely by departmental funds. The authors have no conflicts of interest pursuant to this report. Accepted for publication October 23, 2007.

Revision accepted October 25, 2007. 
A

CUTE epiglottitis is now primarily a disease of adults because of the widespread use of effective Haemophilus influenzae type $\mathrm{b}$ (Hib) vaccines in young children., ${ }^{1,2}$ The incidence of adult acute epiglottitis and epiglottic abscess has increased in recent years. ${ }^{3,4}$ The clinical presentation of adult epiglottitis varies substantially from the pediatric form of the disease. ${ }^{5,6}$ The adult disease displays more generalized oropharyngeal and less selective epiglottic inflammation (termed "supraglottitis"), ${ }^{7}$ the clinical presentation has a more gradual onset (often occurring over days and not hours as observed in children), and airway obstruction requiring placement of an artificial airway occurs far less frequently $(21 \%$ of adults as compared to $68 \%$ of children). ${ }^{5}$ The microbiology of adult supraglottitis is also quite different from pediatric epiglottitis because $H$. influenzae is not the bacterial pathogen responsible for the vast majority of adult cases. ${ }^{5,8}$ Most cases of adult epiglottitis occur in previous healthy adults, ${ }^{3,5,8-}$ 12 although hypertension, diabetes mellitus, immunosuppression, and the presence of an active substance abuse disorder have also been identified as predisposing risk factors. ${ }^{5,9,13}$ In this report, we discuss a patient with acute pseudomembranous supraglottitis complicating recurrent tonsillar carcinoma and describe the ramifications of these disorders on perioperative management. Consent for publication of this report was obtained in accordance with local institutional guidelines where the patient received his care.

\section{Case report}

A cachectic, 54-yr-old, 170-cm, 67-kg man with a history of right tonsil T3N3M0 squamous cell carcinoma presented to our institution for evaluation of a three day history of worsening dyspnea. The cancer was originally treated with chemoradiation therapy followed by a salvage modified right radical neck dissection three years before this admission. A percutaneous gastrostomy tube was subsequently inserted six months before his current presentation because the patient had developed progressive dysphagia and odynophagia complicated by episodes of aspiration pneumonia. However, a computed tomographic (CT) scan performed at the time of the gastrostomy tube placement demonstrated no evidence of tumour recurrence. The patient suffered from a chronic sore throat and hoarseness, and he stated that these symptoms were worse than his baseline condition. The past medical history was notable for moderately severe chronic obstructive pulmonary disease with a bronchospastic component treated with albuterol and ipratroprium bromide inhalers, anemia of chronic disease, essential hypertension, and hypothyroidism treated with levothyroxine.

On physical examination, the patient was febrile $\left(38.9^{\circ} \mathrm{C}\right)$, diaphoretic, and appeared acutely toxic. Stridor and tachypnea were present during slight exertion or mild anxiety. He spoke with shortened word strings and was using accessory respiratory muscles to breathe. The patient was drooling small quantities of saliva while sitting, and his daughters reported that this drooling was more pronounced when he was recumbent. The patient was edentulous, but the soft tissue of his neck was very stiff, his neck mobility was quite limited, and his mouth opening $(<2 \mathrm{~cm})$ was markedly restricted by pain and radiation-induced fibrosis. These findings strongly suggested that conventional direct or fibreoptic laryngoscopy and endotracheal intubation may have been very difficult if not impossible. A healed tracheostomy scar was also present. Minimal air movement, inspiratory stridor, and bilateral wheezing were appreciated during chest auscultation.

A nasal flexible fibreoptic laryngoscopy was performed before the patient was transported to the operating room and revealed a very large, markedly indurated epiglottis almost completely obstructing the glottis. The aryepiglottic folds and false cords were grossly edematous, and a gray pseudomembranous exudate was observed on the glottic surface, epiglottis, and true vocal cords. Irregular mucosa was also observed within the left aryepiglottic fold, suggesting the possibility of tumour recurrence. An arterial blood gas analysis obtained with the patient breathing $2 \mathrm{~L} \cdot \mathrm{min}^{-1} \mathrm{O}_{2}$ by nasal cannula revealed relative hypoxemia, hypercarbia, and normal acid-base status resulting from the combination of respiratory acidosis balanced by chronic metabolic compensation $(\mathrm{pH}$ $=7.419, \mathrm{PaO}_{2}=63 \mathrm{mmHg}, \mathrm{PaCO}_{2}=69 \mathrm{mmHg}$, bicarbonate $\left.=44 \mathrm{mmol} \cdot \mathrm{L}^{-1}\right)$. The white blood cell count was 13,800 cells $\mu \mathrm{L}^{-1}$ with $89 \%$ polymorphonuclear leukocytes. A chest $x$-ray revealed no active pulmonary disease. The patient received intravenous piperacillin-tazobactam (4.5 g) and methylpredisolone $(40 \mathrm{mg})$ before surgery. Because we anticipated difficulty in securing the airway using conventional techniques, the otolaryngology service performed an elective tracheostomy using $1 \%$ lidocaine local anesthesia in the operating room. Oxygen was provided by facemask, but conscious sedation was avoided because of the potential for complete airway obstruction. The patient tolerated the procedure well. After the airway was secured with a \#6 cuffed Shiley tracheostomy tube (Tyco Healthcare, Pleasanton, CA, USA) and bilateral breath sounds were confirmed, general anesthesia was 


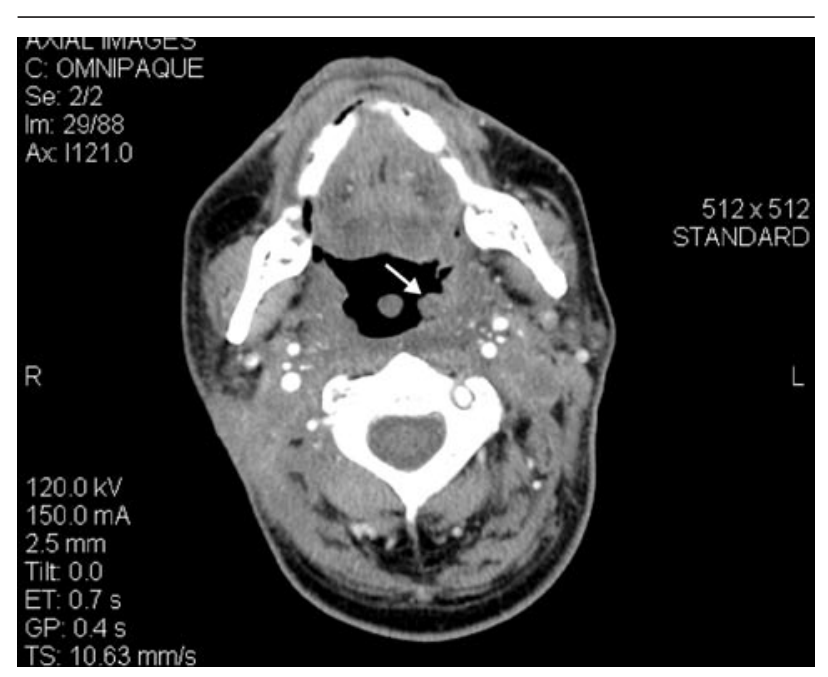

FIGURE I Computed tomographic image with angiographic contrast demonstrating left palatine tonsillar mass (arrow).

induced with propofol and maintained using sevoflurane. A direct laryngoscopy was attempted to further examine the irregular mucosa identified on the left aryepiglottic fold. The epiglottis and supraglottic structures were confirmed to be very large and indurated, but trismus and the presence of tissue edema resulting from the acute infection made the glottis and surrounding structures difficult to visualize. The procedure was abandoned and the patient was transferred to the intensive care unit in stable condition.

The patient rapidly defervesced and his white blood cell count returned to normal within 24 and $48 \mathrm{hr}$, respectively, after antibiotic therapy was initiated. Corticosteroid treatment was continued during the postoperative period. A CT scan of the neck performed on the third postoperative day indicated the presence of a left palatine tonsillar mass (Figure 1) associated with lymphadenopathy and thrombosis of the left internal jugular vein. The epiglottis was diffusely thickened (Figure 2), and also demonstrated ulceration along its left lateral aspect. The patient returned to the operating room 11 days after the tracheostomy for further evaluation of the suspected tumour recurrence. Anesthesia was induced with propofol, fentanyl, and rocuronium, and maintained with sevoflurane. Direct laryngoscopy demonstrated resolution of the infection-induced edema observed during the initial presentation. There was erosion and necrosis within the base of the right tongue, right oropharynx, and epiglottis. Frozen section biopsies revealed chronic inflammation and dysplasia of the right oropharynx as well as invasive squamous cell

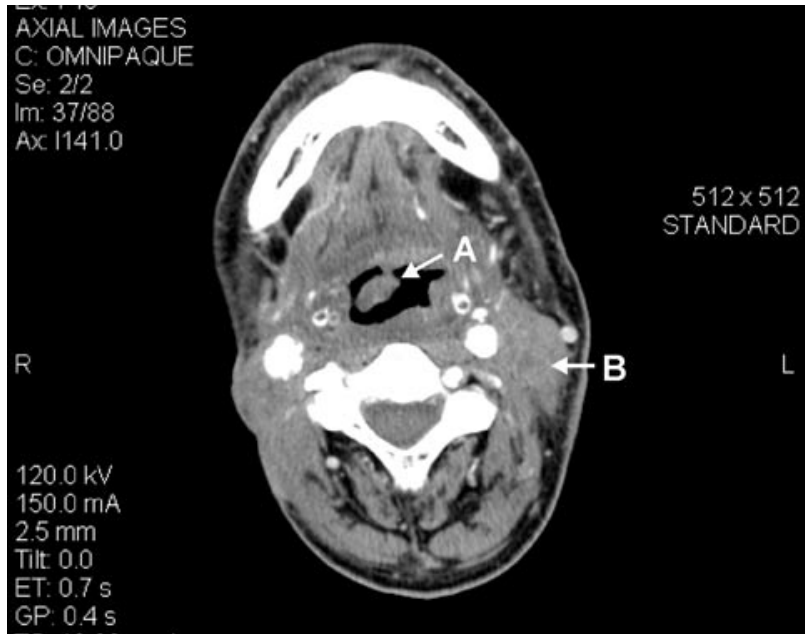

FIGURE 2 Computed tomographic image with angiographic contrast demonstrating the presence of a diffusely thickened epiglottis (bold A with arrow) and contrastenhanced necrotic lymph node (bold B with arrow).

carcinoma within the epiglottis. Examination of the left soft palate also revealed extensive erosion from the left tonsillar region across the epiglottis and the right tongue base. The distal extent of tumour recurrence within the hypopharynx could not be evaluated because severe trismus limited further examination. Permanent pathological tissue sections from the epiglottis and left oropharynx demonstrated moderately to poorly differentiated squamous cell carcinoma. The patient will undergo further chemoradiation therapy for palliative treatment of tumour recurrence.

\section{Discussion}

Acute supraglottitis complicating an advanced recurrent oropharyngeal carcinoma has been rarely reported. Our patient presented with gradually progressive respiratory distress of three days duration, fever, leukocytosis, stridor, tachypnea, and use of accessory respiratory muscles. These findings have been associated previously with airway compromise in adults with epiglottitis. ${ }^{5}$ This patient had a past history of essential hypertension and his recurrent cancer and malnutrition most likely contributed to some degree of immune dysfunction, but he was not diabetic and he did not have a substance abuse disorder. Thus, our patient demonstrated two of four previously recognized risk factors for adult epiglottitis. ${ }^{5,9,13}$ Contralateral spread of tonsillar carcinoma has been described previously, although recurrence is more often ipsilateral because these tumours may present initially with excessive local invasion and associated lymphadenopathy. ${ }^{14}$ 
Controversy persists concerning airway management of previously healthy adults with epiglottitis. ${ }^{6}$ Some investigators have recommended that most patients with mild to moderate signs and symptoms of airway compromise may be managed conservatively with careful monitoring, 5,15,16 while others have argued that elective endotracheal intubation is a safer approach ${ }^{8,17}$ based on a variety of clinical predictors. ${ }^{5,17-19}$ Despite this relative debate, it is intuitively obvious that immediate airway intervention is required for adults with acute epiglottitis and impending airway obstruction, including our patient. In this case, we proceeded directly to elective awake tracheostomy using local anesthesia without conscious sedation. We were convinced that previous radiation therapy-induced tissue fibrosis, severe trismus, and recurrent tonsillar carcinoma in the presence of acute supraglottitic inflammation and edema would have made conventional direct or fibreoptic laryngoscopy and endotracheal intubation impossible. We briefly considered using nasal fibreoptic bronchoscopy for endotracheal intubation because the surgeons had previously performed a nasal fibreoptic laryngoscopy. However, we chose not to attempt this approach because we could not assure adequate upper airway anesthesia to prevent laryngospasm and the resulting loss of airway patency in response to stimulation by additional airway secretions, a fibreoptic bronchoscope, or the endotracheal tube. In our view it would have been unsafe to attempt to anesthetize the hypopharynx and upper airway with a topical local anesthetic, nor was it possible to perform bilateral superior laryngeal nerve blocks in this patient with distorted anatomy secondary to a previous radical neck dissection, radiation therapy, and an acute infectious process. Subsequent attempts at diagnostic laryngoscopy under general anesthesia and neuromuscular blockade were very difficult and confirmed our initial clinical impression.

In contrast to the pediatric form of the disease in which $H$. influenzae is the most frequently identified bacteria, adult epiglottitis is frequently caused by other bacteria (e.g., alpha- or beta-hemolytic Streptococcus, Streptococcus pneumoniae, Nisseria meningitis) in previously healthy patients ${ }^{3,12}$ or more unusual pathogens (e.g., Candida albicans) in immunocompromised patients ${ }^{13,20}$ or those with a history of drug abuse. ${ }^{21,22}$ Most commonly, blood cultures remain negative in patients with adult epiglottitis, ${ }^{5,8,12}$ and cultures obtained directly from the epiglottitis and surrounding tissue during laryngoscopy also fail to identify the responsible bacterial pathogen. ${ }^{7}$ As a result of these data, blood, epiglottic, and oropha- ryngeal cultures were not obtained in our patient and instead, empiric treatment with a broad-spectrum intravenous antibiotic (piperacillin-tazobactam) was instituted in order to provide coverage against $H$. influenzae, Streptococcus species, and Corynebacterium diphtheriae.

In summary, the current case emphasizes that establishing a surgical airway under controlled operating conditions may be the optimal approach to the perioperative management of imminent airway obstruction by acute supraglottitis complicating recurrent oropharyngeal cancer. Handling such high-risk airway situations requires a prudent, well-conceived strategy based on the clinician's careful assessment, level of comfort, and experience.

\section{References}

1 Adams WG, Deaver KA, Cochi SL, et al. Decline of childhood Haemophilus influenzae type b (Hib) disease in the Hib vaccine era. JAMA 1993; 269: 2216.

2 Murphy TV, White KE, Pastor P, et al. Declining incidence of Haemophilus influenzae type $\mathrm{b}$ disease since introduction of vaccination. JAMA 1993; 269: 246-8.

3 Berger G, Landan T, Berger S, Finkelstein $\Upsilon$, Bernheim $J$, Ophir $D$. The rising incidence of adult acute epiglottitis and epiglottic abscess. Am J Otolaryngol 2003; 24: $374-83$.

4 McVernon J, Slack MP, Ramsay ME. Changes in the epidemiology of epiglottitis following introduction of Haemophilus influenzae type $\mathrm{b}$ (Hib) conjugate vaccines in England: a comparison of two data sources. Epidemiol Infect 2006; 134: 570-2.

5 Mayo-Smith MF, Spinale JW, Donskey CJ, Yukawa M, Li $R H$, Schiffman FJ. Acute epiglottitis. An 18-year experience in Rhode Island. Chest 1995; 108: 1640-7.

6 Park KW, Darvish A, Lowenstein E. Airway management for adult patients with acute epiglottitis: a 12-year experience at an academic medical center (1984-1995). Anesthesiology 1998; 88: 254-61.

7 Shapiro J, Eavey RD, Baker AS. Adult supraglottitis. A prospective analysis. JAMA 1988; 259: 563-7.

8 Frantz TD, Rasgon BM, Quesenberry CP Jr. Acute epiglottitis in adults. Analysis of 129 cases. JAMA 1994; 272: 1358-60.

9 Chang $\Upsilon L$, Lo SH, Wang PC, Shu $Y H$. Adult acute epiglottitis: experiences in a Taiwanese setting. Otolaryngol Head Neck Surg 2005; 132: 689-93.

10 Hebert PC, Ducic Y, Boispert D, Lamothe A. Adult epiglottitis in a Canadian setting. Laryngoscope 1998; 108: 64-9.

11 Kucera CM, Silverstein MD, Jacobsen RM, Wollan 
PC, Jacobsen SJ. Epiglottitis in adults and children in Olmsted County, Minnesota, 1976 through 1990. Mayo Clin Proc 1996; 71: 1155-61.

12 Solomon P, Weisbrod M, Irish JC, Gullano PJ. Adult epiglottitis: the Toronto Hospital experience. J Otolaryngol 1998; 27: 332-6.

13 Laing RB, Wardrop PJ, Welby PD, Brettle RP. Stridor in patients with HIV infection. J Laryngol Otol 1995; 109: 1197-9.

14 Schantz SP, Harrison LB, Forastiere AA. Tumors of the nasal cavity and paranasal sinuses, nasopharynx, oral cavity, and oropharynx. In: Devita VT Jr, Hellman S, Rosenberg SA (Eds). Cancer Principles and Practice of Oncology, 6th ed. Philadelphia: Lippincott Williams and Wilkins; 2001: 797-860.

15 Wolf M, Strauss B, Kronenberg J, Leventon G.

Conservative management of adult epiglottitis. Laryngoscope 1990; 100: 183-5.

16 Torkkeli T, Ruoppi P, Nuutinen J, Kari A. Changed clinical course and current treatment of acute epiglottitis in adults: a 12-year experience. Laryngoscope 1994; 104: 1503-6.
17 Kass EG, McFadden EA, Jacobson S, Toobil RJ. Acute epiglottitis in the adult: experience with a seasonal presentation. Laryngoscope 1993; 103: 841-4.

18 Deeb ZE, Yenson AC, DeFries HO. Acute epiglottitis in the adult. Laryngoscope 1985; 95: 289-91.

19 Crosby E, Reid D. Acute epiglottitis in the adult: is intubation mandatory? Can J Anaesth 1991; 38: 914-8.

20 Gagnon R, Bedard PM, Cote L, Lavoie A, Hebert J. Recurrent acute epiglottitis in adults: defective antibody response. Ann Allergy Asthma Immunol 2002; 88: 513-7.

21 Savitt DL, Colagiovanni S. Crack cocaine-related epiglottitis. Ann Emerg Med 1991; 20: 322-3.

22 Ames WA, Ward VM, Tranter RM, Street M. Adult epiglottitis: an under-recognized, life-threatening condition. Br J Anaesth 2000; 85: 795-7.

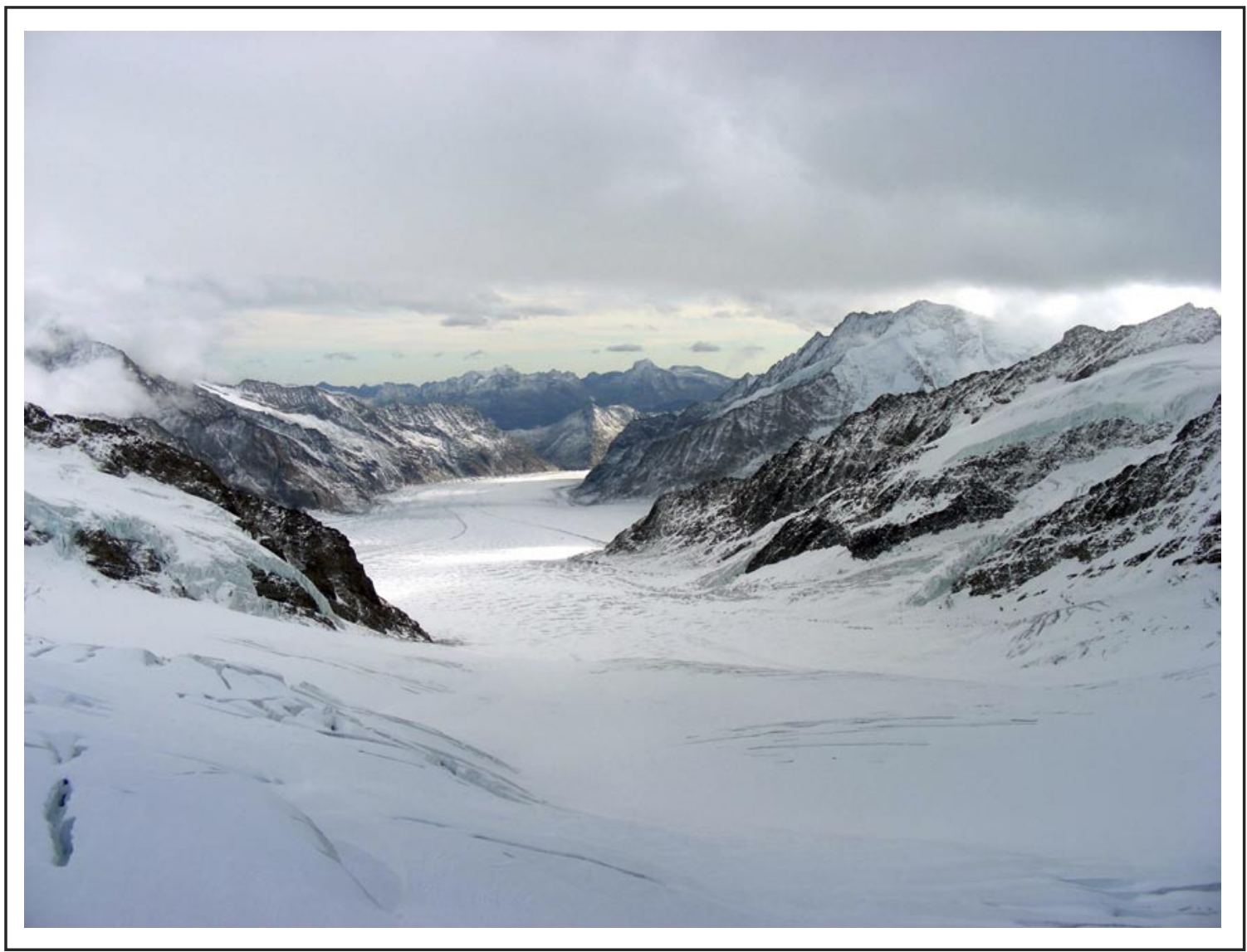

Glacier, Jungfrajoch - Switzerland 